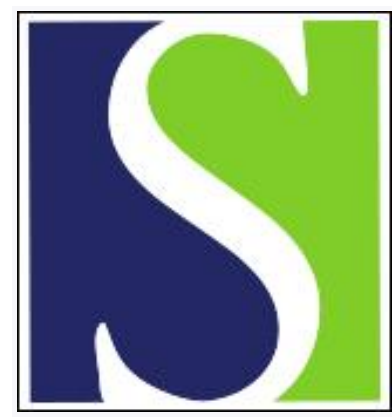

Scand J Work Environ Health 2012;38(6):590-599

https://doi.org/10.5271/sjweh.3313

Published online: 09 Jul 2012, Issue date: 01 Nov 2012

Characteristics of the Million Women Study participants who have and have not worked at night

by Wang X-S, Travis RC, Reeves G, Green J, Allen NE, Key TJ, Roddam AW, Beral V

Few studies have reported on the associations between night work and risk factors for chronic disease. We found that women who had ever worked at night were substantially different from those who had not. Many of the differences, for example, in socioeconomic status, smoking and obesity would put night workers at increased risks of cancer, vascular disease and other common conditions.

Affiliation: Cancer Epidemiology Unit, University of Oxford, Oxford OX3 7L, United Kingdom. ruth.travis@ceu.ox.ac.uk

Refers to the following texts of the Journal: 2008;34(1):5-22 2009;35(3):163-179 2010;36(2):134-141

The following articles refer to this text: 2015;41(3):259-267; 2015;41(3):268-279; 2017;43(2):127-135; 2020;46(3):293-301; 2020;46(6):570-578

Key terms: cancer; cohort; Million Women Study; night work; risk factor; shift work; sleep; vascular disease

This article in PubMed: www.ncbi.nlm.nih.gov/pubmed/22772745

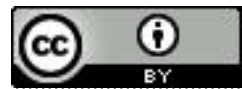




\title{
Characteristics of the Million Women Study participants who have and have not worked at night
}

\author{
by Xiao-Si Wang, PhD, ${ }^{1}$ Ruth C Travis, DPhil, ${ }^{1}$ Gillian Reeves, PhD, ${ }^{1}$ Jane Green, MD, ${ }^{1}$ Naomi E Allen, \\ DPhil, ${ }^{1}$ Tim J Key, DPhil, ${ }^{1}$ Andrew W Roddam, DPhil, ${ }^{1}$ Valerie Beral, FRS ${ }^{1}$
}

\begin{abstract}
Wang X-S, Travis RC, Reeves G, Green J, Allen NE, Key TJ, Roddam AW, Beral V. Characteristics of the Million Women Study participants who have and have not worked at night. Scand J Work Environ Health. 2012;38(6):590599. doi:10.5271/sjweh.3313
\end{abstract}

Objectives The aim of this study was to compare the characteristics of women who had and had not worked at night in terms of their risk factors for common disease, indicators of general health, social activities, employment, and sleep behavior.

Methods The Million Women Study is a large prospective cohort study of women's health in the United King dom with 1.3 million women recruited during 1996-2001 (aged 50-64 years) through 66 National Health Service breast screening centers. We analyzed the data from a random sample of 41652 participants who, in 2009-2010, reported their history of night work.

Results Of the participants, 1 in 8 women (13\%) reported that they had ever worked at night and 1 in $50(2 \%)$ reported working at night for $\geq 20$ years. For 33 sociodemographic, behavioral, reproductive, and hormonal factors examined, 20 showed highly significant differences between "ever" and "never" night workers $(\mathrm{P}<0.0001) ; 12$ showed significant trends by duration of night work $(\mathrm{P}<0.01)$. In particular, compared to women who had never worked at night, women who had worked at night were more likely to (i) be of lower socioeconomic status [the odds ratio (OR) for ever versus never night workers of being in the lowest third of socioeconomic status was $1.15,99 \%$ confidence interval (95\% CI) 1.06-1.25]; (ii) have ever used hormone replacement therapy (HRT) for the menopause (OR 1.43, 99\% CI 1.33-1.55); (iii) be current smokers (OR 1.37, 99\% CI 1.19-1.58); and (iv) be obese (OR 1.26, 99\% CI 1.15-1.37). Compared to women who had never worked at night, women who had worked at night for $\geq 20$ years were more likely to be (i) of lower socioeconomic status (OR 1.28, 99\% CI 1.04-1.57); (ii) nulliparous (OR $1.47,99 \%$ CI 1.12-1.91); (iii) current smokers (OR 1.63, 99\% CI 1.18-2.25); and (iv) obese (OR 1.55, 99\% CI 1.25-1.93). Former night workers were more likely than never night workers to report a range of sleep disturbances, including poor quality of sleep (OR 1.15, 99\% CI 1.01-1.31) and having to take medication to sleep (OR 1.35, 99\% CI 1.15-1.60).

Conclusions Women who reported having worked at night were substantially different from those who reporting never having worked at night and many of the differences would put "ever night workers" at increased risks of cancer, vascular disease, and many other common conditions.

Key terms cancer; cohort; night work; risk factor; shift work; sleep; vascular disease.

Shift work, including night work, has been proposed as a risk factor for a number of diseases. The published epidemiological evidence is suggestive, but not conclusive for an association between night work and increased risks of breast cancer and vascular disease, and evidence is limited for other diseases (1-3). A number of mechanisms may underlie these associations, including those related to suppressed melatonin production, sleep disturbances, and confounding by other behavioral or lifestyle factors (4-6).

The aim of this study was to compare participants of the Million Women Study cohort who have and have not worked at night ("ever" versus "never" night workers) in terms of their risk factors for common diseases, indicators of general health, social activities, employment, and sleep.

1 Cancer Epidemiology Unit, University of Oxford, Oxford, OX3 7LF, United Kingdom.

Correspondence to: Ruth C Travis, Cancer Epidemiology Unit, University of Oxford, Oxford OX3 7L, United Kingdom. [E-mail: ruth. travis@ceu.ox.ac.uk] 


\section{Methods}

\section{The Million Women Study}

During 1996-2001, a total of 1.3 million women aged 50-64 years who had been invited for routine screening for breast cancer at 66 screening centers in England and Scotland completed the recruitment questionnaire. The questionnaire asked about various characteristics, including anthropometric and reproductive factors, and other personal characteristics. Since recruitment, four questionnaires have been sent to the cohort participants approximately every 3-4 years to update and expand information on various factors. The study design and methods and the survey questionnaires can be found at the study's website (www.millionwomenstudy.org). The Oxford and Anglia Multi-Centre Research and Ethics Committee and the Eastern Multi-Centre Research and Ethics Committee granted ethics approval for the work.

\section{Study subjects and data collection}

The fourth survey questionnaire is being sent out in batches to the study population, beginning in 2009, and included questions for the first time about women's history of night work. There is not a universal definition of shift work and a variety of definitions have been used in previous shift work studies, depending on the main hypothesis of interest, study design, and study population. The main aim of the Million Women Study shift work project is to assess the hypothesis that regular night work, particularly long-term night work, is associated with increased risk for breast cancer and cardiovascular disease. Participants were therefore asked "Have you ever regularly worked at night or on night shifts (at any time between midnight and 06:00 hours, for at least 3 nights per month)?". Those who answered "yes" were asked about the duration ("Over how many years in total?") and timing of night work ("When did you last work at night?"). Previous large prospective cohort studies of night work and breast cancer have also assessed duration of regular night work, with regular night work being similarly defined as night work undertaken $\geq 3$ nights per month $(7,8)$. The fourth survey questionnaire also asked about the women's current weight, height, alcohol consumption, smoking history, physical activity, use of hormone therapy for the menopause (HRT), indicators of general health, major life events, social contacts, sleep (duration at night, quality and difficulties), chronotype (a person's internal circadian phase, ie, whether a women considers herself to be a morning person, more of a morning than evening person, more of an evening than morning person or more of an evening person), and whether they had worked in certain specified jobs for $\geq 10$ years.
These analyses include responses from a sample of 41652 participants (selected at random by their day and month of birth) who replied to a questionnaire sent out between September 2009 and March 2010. For this random sample, the processing of questionnaire data was accelerated specifically for these analyses. The remainder of the questionnaire data is currently being processed, but will take several years to complete. We examined the associations of reported night work history with other factors reported by participants during the follow-up period.

\section{Statistical analysis}

The STATA computing 2007, release 11 package (StataCorp, College Station, TX, USA) was used for all analyses. We categorized the study participants into those who reported having ever and never done night work. Based on the hypothesis that longer duration of night work may be associated with a higher risk of common disease, we also categorized ever night workers by duration: short( $<10$ years), medium- (10-19 years) and long-duration night workers ( $\geq 20$ years).

Firstly, crude distributions of various characteristics by night work history were calculated. Secondly, logistic regression models were used to calculate adjusted odds ratios (OR) and $95 \%$ confidence intervals $(95 \% \mathrm{CI})$ for various characteristics by comparing (i) ever versus never night workers (the reference group); and (ii) three categories of ever versus never night workers (the reference group). In order to examine differences between ever and never night workers beyond those explained by age and socioeconomic status, analyses of all other factors by night work status were adjusted for age (continuous) and socioeconomic status (based on tertiles of the Townsend deprivation index). The Townsend Index provides a measure of material deprivation and disadvantage by postcode of residence and is based on four different variables taken from the Census, including unemployment, non-car ownership, non-home ownership, and household overcrowding. The four variables combine to form an overall score for a postcode area and allows different areas to be ranked in relation to one another, with a higher score indicating a higher level of deprivation (9). For continuous variables, women were divided into two groups based on established cut-offs for the comparisons: age at menarche $(<13, \geq 13$ years), number of children $(<3, \geq 3)$, age at first birth $(<25, \geq 25$ years among parous women), height $(<165 \mathrm{~cm}, \geq 165 \mathrm{~cm})$, body mass index $(<30, \geq 30$ $\left.\mathrm{kg} / \mathrm{m}^{2}\right)$, alcohol consumption ( $<14, \geq 14$ drinks per week), vigorous physical activity (none, any per week), moderate physical activity ( $\leq 1,>1$ hour per week), night time sleep duration $(<6, \geq 6$ hours per night; or $<8, \geq 8$ hours per night) and napping (none, any per week). Tests for linear trend in these variables across night work duration 
categories were obtained by scoring the night work duration categories with values equal to the median value of the continuous variable within that night work duration category. In view of the multiple comparisons, which may give rise to false positive associations, and the large sample size that may result in statistically but not biologically significant associations, $99 \% \mathrm{CI}$ were given for each $\mathrm{OR}$, and P-values of $<0.01$ were considered statistically significant. All P-values were obtained from 2-sided tests.

\section{Results}

\section{Night work}

These analyses included 41652 women who provided information on history of night work, at a mean age of 68.6 years. Among these women, 1 in 8 (13.2\%) reported having ever worked at night. Among the 5497 women who reported having ever worked at night, 5337 (97.1\%) provided information on duration of night work and/or time since last working at night. Table 1 shows the distribution of night work duration and time since last working at night among ever night workers. The median duration of night work was 5 years $\left(25^{\text {th }}-75^{\text {th }}\right.$ percentile range: 3-11 years) and the median duration of time since last working at night was 20 years $\left(25^{\text {th }}-75^{\text {th }}\right.$ percentile range: $10-39$ years). Among the 41652 women, $4.3 \%$ reported working at night for $\geq 10$ years and $1.8 \%$ reported working at night for $\geq 20$ years. Of those who reported having worked at night, $49 \%$ reported having worked as a nurse for $\geq 10$ years and among those women who reported having worked at night for $\geq 20$ years, $64 \%$ reported having worked as a nurse for $\geq 10$ years.

\section{Characteristics by night work status and duration of night work}

Characteristics of the study population by night work status and duration of night work are shown in tables $2 a, 2 b, 3 a$, and $3 b$. Ever and never night workers differed significantly by a number of sociodemographic, reproductive, hormonal, anthropometric, and lifestyle factors including major risk factors for cancer and vascular disease, as well as by work-related and social factors, health indicators, and sleep characteristics. We compared the likelihood of having various characteristics according to night work history using adjusted OR (tables 4 and 5). For 33 sociodemographic, behavioral, reproductive, and hormonal factors examined, 20 showed highly significant differences between ever and never night workers $(\mathrm{P}<0.0001)$ whereas none would be expected by chance at this level of significance; 12 showed significant trends by duration of night work
Table 1. Reported night work among 41652 participants in the Million Women Study. ${ }^{\text {a }}$

\begin{tabular}{lrc}
\hline & $\%$ & Number ${ }^{\mathrm{a}}$ \\
\cline { 2 - 3 } Ever night work & 13.2 & 5497 \\
Duration of night work (years) & & \\
$\leq 1$ & 12.8 & 681 \\
$2-4$ & 33.3 & 1779 \\
$5-9$ & 20.2 & 1080 \\
$10-14$ & 13.5 & 719 \\
$15-19$ & 6.3 & 334 \\
$20-29$ & 8.8 & 470 \\
$30-39$ & 3.8 & 203 \\
$\geq 40$ & 1.3 & 71 \\
Time since last working & & \\
at night (years) & & 245 \\
Currently working & 4.6 & 925 \\
$1-9$ & 17.3 & 1212 \\
$10-19$ & 22.7 & 1639 \\
$20-39$ & 30.7 & 1316 \\
$\geq 40$ & 24.7 & \\
\hline
\end{tabular}

${ }^{a}$ Of the 5497 ever night workers, 5337 (97.1\%) provided information on duration of night work and/or time since last working at night.

among ever night workers $(\mathrm{P}<0.01)$, whereas 1 or 0 would be expected by chance at this level of significance. For sleep and related factors examined, 4 out of 10 showed highly significant differences between ever and never night workers $(\mathrm{P}<0.0001)$, and 4 out of 10 showed significant trends by duration of night work among ever night workers $(\mathrm{P}<0.01)$.

\section{Sociodemographic factors}

Ever night workers, especially those with a longer duration of night work, were more likely to come from lower socioeconomic groups than never night workers $(30.7 \%$ of long-, $31.8 \%$ of medium-, and $26.8 \%$ of short-duration night workers versus $25.7 \%$ of never night workers were in the lowest third of the socioeconomic scale) (tables $2 \mathrm{a}$ and $2 \mathrm{~b}$ ). After adjusting for age, differences in socioeconomic status remained between the night work groups $(\mathrm{P}<0.0001)$ (table 4$)$. Ever night workers were also significantly less likely to hold a college/ university degree $(\mathrm{P}<0.0001)$. Given these observations, we adjusted for age and socioeconomic status (tertile of Townsend Index) for all the other factors.

Ever night workers were significantly more likely to have been in paid employment and were also significantly more likely to report that the paid employment involved physical effort. Ever night workers were significantly less likely than never night workers to be married or living with a partner and were significantly more likely to have experienced divorce or permanent separation in the five years prior to the fourth survey. There was no significant difference between ever and never night workers in the likelihood of having experienced death of spouse or partner in the five years prior to the fourth survey. 
Table 2a. Characteristics of women included in the analyses by night work history. [SD=standard deviation.]

\begin{tabular}{|c|c|c|c|c|c|c|c|c|}
\hline \multirow[t]{2}{*}{ Characteristic } & \multicolumn{4}{|c|}{ Never night workers ( $\mathrm{N}=36$ 155) } & \multicolumn{4}{|c|}{ Ever night workers ( $N=5497)$} \\
\hline & $\mathrm{N}$ & $\%$ & Mean & SD & $\mathrm{N}$ & $\%$ & Mean & SD \\
\hline $\begin{array}{l}\text { Sociodemographic factors } \\
\text { Year of birth }^{\mathrm{a}} \\
\text { Socioeconomic status, in the lower third a }^{\text {a }} \\
\text { With college/university degree }^{\text {a }} \\
\text { In paid employment at age } 60^{\mathrm{b}} \\
\text { In paid employment at age } 65^{\mathrm{c}} \\
\text { In paid employment at age } 69^{\mathrm{d}} \\
\text { Any physical effort at work (for paid employment) }{ }^{\mathrm{b}} \\
\text { Married/living with a partner }{ }^{\mathrm{c}} \\
\text { Divorce/permanent separation in last } 5 \text { years }^{\mathrm{d}} \\
\text { Death of spouse/partner in last } 5 \text { years }^{\mathrm{d}}\end{array}$ & $\begin{array}{r}929 \\
6366 \\
14529 \\
8172 \\
5358 \\
2154 \\
21996 \\
969 \\
2933\end{array}$ & $\begin{array}{r}25.7 \\
34.7 \\
46.7 \\
28.6 \\
15.0 \\
43.0 \\
78.1 \\
2.8 \\
8.4\end{array}$ & 1941.1 & 4.7 & $\begin{array}{r}1564 \\
769 \\
2429 \\
1423 \\
1018 \\
577 \\
3103 \\
204 \\
445\end{array}$ & $\begin{array}{r}28.5 \\
24.2 \\
51.6 \\
32.6 \\
18.7 \\
63.1 \\
72.5 \\
4.0 \\
8.4\end{array}$ & 1941.4 & 4.6 \\
\hline $\begin{array}{l}\text { Reproductive and hormonal factors } \\
\text { Age at menarche (years) }{ }^{\text {a }} \\
\text { Nulliparous a } \\
\text { Number of children a } \\
\text { Age at first birth (for parous women) (years) }{ }^{\text {a }} \\
\text { Ever oral contraceptive use a } \\
\text { Ever use of hormone therapy for menopause }{ }^{d}\end{array}$ & $\begin{array}{l}21599 \\
18243\end{array}$ & $\begin{array}{l}60.1 \\
51.5\end{array}$ & $\begin{array}{r}12.9 \\
\\
2.1 \\
24.4\end{array}$ & $\begin{array}{l}1.6 \\
\\
1.2 \\
4.2\end{array}$ & $\begin{array}{l}3584 \\
3270\end{array}$ & $\begin{array}{l}65.6 \\
60.6\end{array}$ & $\begin{array}{r}12.9 \\
\\
2.3 \\
24.2\end{array}$ & $\begin{array}{l}1.7 \\
1.3 \\
4.4\end{array}$ \\
\hline $\begin{array}{l}\text { Anthropometric and lifestyle factors } \\
\text { Height }(\mathrm{cm})^{d} \\
\text { Body mass index }\left(\mathrm{kg} / \mathrm{m}^{2}\right)^{d} \\
\text { Current smoker }^{d} \\
\text { Alcohol drinks per week }{ }^{d} \\
\text { Hours of vigorous physical activity per week }{ }^{d} \\
\text { Hours of moderate physical activity per week }{ }^{d}\end{array}$ & 2196 & 6.2 & $\begin{array}{r}161.6 \\
26.6 \\
\\
5.0 \\
1.4 \\
7.0\end{array}$ & $\begin{array}{l}6.7 \\
4.8 \\
\\
6.8 \\
3.1 \\
6.3\end{array}$ & 463 & 8.6 & $\begin{array}{r}161.8 \\
27.3 \\
\\
5.2 \\
1.6 \\
7.1\end{array}$ & $\begin{array}{l}6.7 \\
5.2 \\
7.3 \\
3.3 \\
6.4\end{array}$ \\
\hline $\begin{array}{l}\text { Social contact and activities } \\
\text { In contact with family or friends on most days }{ }^{d} \\
\text { In contact with others on most days }{ }^{d} \\
\text { Do voluntary work }{ }^{c} \\
\text { Attend adult education }{ }^{c} \\
\text { Belong to religious group }{ }^{c} \\
\text { Attend leisure group }{ }^{c, e} \\
\text { Attend fitness group }{ }^{c, f} \\
\text { Almost always feel happy }{ }^{d}\end{array}$ & $\begin{array}{r}23711 \\
2925 \\
2948 \\
4080 \\
5564 \\
8231 \\
10373 \\
17375\end{array}$ & $\begin{array}{r}65.9 \\
8.6 \\
22.0 \\
11.3 \\
15.4 \\
22.8 \\
28.7 \\
48.5\end{array}$ & & & $\begin{array}{r}3818 \\
548 \\
1406 \\
728 \\
1041 \\
1276 \\
1604 \\
2559\end{array}$ & $\begin{array}{l}70.0 \\
10.5 \\
25.6 \\
13.2 \\
18.9 \\
23.2 \\
29.2 \\
47.0\end{array}$ & & \\
\hline $\begin{array}{l}\text { Health indicators } \\
\text { Self-assessed poor overall health }{ }^{d} \\
\text { Self-assessed poor physical fitness }^{d} \\
\text { Diabetes }^{d} \\
\text { High blood pressure }^{d}\end{array}$ & $\begin{array}{r}764 \\
2612 \\
2637 \\
14537\end{array}$ & $\begin{array}{r}2.1 \\
7.4 \\
7.3 \\
40.2\end{array}$ & & & $\begin{array}{r}176 \\
446 \\
489 \\
2265\end{array}$ & $\begin{array}{r}3.2 \\
8.2 \\
8.9 \\
41.2\end{array}$ & & \\
\hline
\end{tabular}

a Values are for information reported at the first (baseline) survey (average age 55.9 years).

${ }^{b}$ Values are for information reported at the second survey (average age 59.8 years).

${ }^{c}$ Values are for information reported at the third survey (average age 64.9 years).

${ }^{\mathrm{d}}$ Values are for information reported at the fourth survey (average age 68.6 years).

${ }^{e}$ Leisure groups including music, singing, dancing, art, craft and bingo groups.

${ }^{\mathrm{t}}$ Fitness groups including fitness, aerobics, yoga, pilates and sports groups.

\section{Reproductive and hormonal factors}

Compared to never night workers, ever night workers were significantly more likely to have $\geq 3$ children and ever used oral contraceptives and HRT. There was no significant difference between ever and never night workers in the likelihood of having menarche at $<13$ years of age or having first given birth at age $\geq 25$ years (among parous women).

\section{Anthropometric and lifestyle factors}

Ever night workers were significantly more likely than never night workers to be obese, to be current smokers, and to do vigorous physical activity. There was no significant difference between ever and never night workers in their height or alcohol consumption.

\section{Social contacts, activities, and related factors}

Compared to never night workers, ever night workers were significantly more likely to have frequent contact with other people. Ever night workers were also significantly more likely to do voluntary work, take part in adult education classes, and belong to a religious group. There was no significant difference between 
Table $\mathbf{2 b}$. Characteristics of women included in these analyses by night work duration. [SD=standard deviation]

\begin{tabular}{|c|c|c|c|c|c|c|c|c|c|c|c|c|}
\hline \multirow[t]{3}{*}{ Characteristic } & \multicolumn{12}{|c|}{ Ever night workers by night work duration } \\
\hline & \multicolumn{4}{|c|}{$<10$ years $(\mathrm{N}=3540)$} & \multicolumn{4}{|c|}{$10-19$ years $(N=1053)$} & \multicolumn{4}{|c|}{$\geq 20$ years $(\mathrm{N}=744)$} \\
\hline & $\mathrm{N}$ & $\%$ & Mean & SD & $\mathrm{N}$ & $\%$ & Mean & SD & $\mathrm{N}$ & $\%$ & Mean & SD \\
\hline \multicolumn{13}{|l|}{ Sociodemographic factors } \\
\hline Year of birth a & & & 1941.3 & 4.6 & & & 1941.5 & 4.5 & & & 1941.6 & 4.6 \\
\hline Socioeconomic status, in the lower third a & 947 & 26.8 & & & 335 & 31.8 & & & 228 & 30.7 & & \\
\hline With college/university degree a & 522 & 24.5 & & & 137 & 24.5 & & & 91 & 22.3 & & \\
\hline In paid employment at age $60^{\mathrm{b}}$ & 1528 & 49.5 & & & 472 & 53.8 & & & 373 & 60.8 & & \\
\hline In paid employment at age $65^{c}$ & 901 & 31.4 & & & 275 & 34.1 & & & 219 & 38.6 & & \\
\hline In paid employment at age $69 \mathrm{~d}$ & 633 & 18.1 & & & 214 & 20.5 & & & 153 & 20.7 & & \\
\hline $\begin{array}{l}\text { Any physical effort at work (for paid } \\
\text { employment) }{ }^{b}\end{array}$ & 321 & 56.7 & & & 133 & 71.9 & & & 111 & 76.0 & & \\
\hline Married/living with a partner ${ }^{c}$ & 2092 & 74.1 & & & 545 & 69.5 & & & 391 & 69.6 & & \\
\hline Divorce/permanent separation in last 5 years $d$ & 123 & 3.7 & & & 43 & 4.4 & & & 31 & 4.4 & & \\
\hline Death of spouse/partner in last 5 years ${ }^{d}$ & 282 & 8.3 & & & 92 & 9.2 & & & 59 & 8.2 & & \\
\hline \multicolumn{13}{|l|}{ Reproductive and hormonal factors } \\
\hline Age at menarche (years) ${ }^{\text {a }}$ & & & 12.9 & 1.6 & & & 12.9 & 1.7 & & & 13.0 & 1.7 \\
\hline Nulliparous a & 336 & 9.5 & & & 135 & 12.8 & & & 115 & 15.5 & & \\
\hline Number of children a & & & 2.3 & 1.2 & & & 2.2 & 1.4 & & & 2.1 & 1.3 \\
\hline Age at first birth (for parous women) (years) a & & & 24.2 & 4.4 & & & 24.1 & 4.5 & & & 24.1 & 4.5 \\
\hline Ever oral contraceptive use a & 2354 & 66.8 & & & 683 & 65.4 & & & 459 & 61.8 & & \\
\hline Ever use of hormone therapy for menopause ${ }^{d}$ & 2114 & 60.8 & & & 624 & 60.2 & & & 436 & 59.8 & & \\
\hline \multicolumn{13}{|l|}{ Anthropometric and lifestyle factors } \\
\hline Height $(\mathrm{cm})^{d}$ & & & 161.9 & 6.6 & & & 161.8 & 6.9 & & & 161.5 & 6.9 \\
\hline Body mass index $\left(\mathrm{kg} / \mathrm{m}^{2}\right)^{d}$ & & & 27.1 & 5.0 & & & 27.5 & 5.4 & & & 27.9 & 5.7 \\
\hline Current smoker d & 263 & 7.6 & & & 110 & 10.7 & & & 74 & 10.4 & & \\
\hline Alcohol drinks per week ${ }^{d}$ & & & 5.4 & 7.4 & & & 4.7 & 6.9 & & & 5.3 & 7.5 \\
\hline Hours of vigorous physical activity per week d & & & 1.5 & 3.1 & & & 1.6 & 3.5 & & & 2.0 & 3.6 \\
\hline Hours of moderate physical activity per week ${ }^{d}$ & & & 7.1 & 6.3 & & & 7.3 & 6.7 & & & 7.0 & 6.4 \\
\hline \multicolumn{13}{|l|}{ Social contact and activities } \\
\hline In contact with family or friends on most days ${ }^{d}$ & 2455 & 69.7 & & & 735 & 70.1 & & & 518 & 70.3 & & \\
\hline In contact with others on most days ${ }^{d}$ & 364 & 10.7 & & & 92 & 9.3 & & & 78 & 11.2 & & \\
\hline Do voluntary work ${ }^{c}$ & 971 & 27.4 & & & 248 & 23.6 & & & 152 & 20.4 & & \\
\hline Attend adult education c & 500 & 14.1 & & & 129 & 12.3 & & & 87 & 11.7 & & \\
\hline Belong to religious group ${ }^{c}$ & 709 & 20.0 & & & 180 & 17.1 & & & 124 & 16.7 & & \\
\hline Attend leisure group $c, e$ & 873 & 24.7 & & & 227 & 21.6 & & & 144 & 19.4 & & \\
\hline Attend fitness group $c, f$ & 1072 & 30.3 & & & 279 & 26.5 & & & 212 & 28.5 & & \\
\hline Almost always feel happy d & 1693 & 48.2 & & & 475 & 45.5 & & & 326 & 44.6 & & \\
\hline \multicolumn{13}{|l|}{ Health indicators } \\
\hline Self-assessed poor overall health ${ }^{d}$ & 107 & 3.1 & & & 36 & 3.5 & & & 17 & 2.3 & & \\
\hline Self-assessed poor physical fitness ${ }^{d}$ & 275 & 7.9 & & & 89 & 8.6 & & & 58 & 8.0 & & \\
\hline Diabetes ${ }^{d}$ & 274 & 7.7 & & & 120 & 11.4 & & & 69 & 9.3 & & \\
\hline High blood pressure ${ }^{d}$ & 1411 & 39.9 & & & 439 & 41.7 & & & 336 & 45.2 & & \\
\hline
\end{tabular}

a Values are for information reported at the first (baseline) survey (average age 55.9 years).

bValues are for information reported at the second survey (average age 59.8 years).

c Values are for information reported at the third survey (average age 64.9 years).

${ }^{d}$ Values are for information reported at the fourth survey (average age 68.6 years).

e Leisure groups including music, singing, dancing, art, craft and bingo groups.

${ }^{\mathrm{f}}$ Fitness groups including fitness, aerobics, yoga, pilates and sports groups.

ever and never night workers in attendance of leisure or fitness groups or in reporting that they almost always felt happy.

\section{Health indicators}

Ever night workers were significantly more likely than never night workers to report poor overall health and to report having had diabetes. There was no significant difference between ever and never night workers in the likelihood of reporting poor physical fitness.

\section{Sleep characteristics}

In order to investigate possible persistent differences in the sleep characteristics by night work history, we compared the sleep characteristics of former and never night workers, excluding women who reported working at night in the last 10 years. Former night workers were significantly more likely to have a relatively short duration of sleep ( $<6$ hours per night; $\mathrm{P}<0.0001)$ and significantly less likely to have a relatively long duration of sleep ( $\geq 8$ hours per night; $\mathrm{P}=0.0006$ ) than never night workers. There was 
Table 3a. Sleep-related characteristics among former night workers by night work history. Women who reported having worked at night in the last 10 years were excluded from the analyses. Values are for information reported at the fourth survey (average age of 68.6 years). [SD=standard deviation]

\begin{tabular}{|c|c|c|c|c|c|c|c|c|}
\hline \multirow[t]{2}{*}{ Characteristic } & \multicolumn{4}{|c|}{ Never night workers ( $\mathrm{N}=36$ 155) } & \multicolumn{4}{|c|}{ Former night workers ( $\mathrm{N}=4327$ ) } \\
\hline & $\mathrm{N}$ & $\%$ & Mean & SD & $\mathrm{N}$ & $\%$ & Mean & SD \\
\hline Sleep duration (hours/night) & & & 6.8 & 1.2 & & & 6.6 & 1.3 \\
\hline Number of naps per week & & & 2.1 & 2.7 & & & 2.2 & 2.9 \\
\hline Poor quality of sleep & 3883 & 10.8 & & & 528 & 12.3 & & \\
\hline Take medication to sleep on most days & 1861 & 5.4 & & & 302 & 7.2 & & \\
\hline Have trouble falling asleep on most days & 6514 & 19.0 & & & 842 & 20.4 & & \\
\hline Wake up too early \& cannot fall asleep on most days & 8081 & 23.8 & & & 1033 & 25.3 & & \\
\hline Feel refreshed in the morning on most days & 21847 & 63.8 & & & 2551 & 61.7 & & \\
\hline Almost always feel tired during the day & 1206 & 3.4 & & & 265 & 4.8 & & \\
\hline More evening than morning/evening types & 10455 & 30.0 & & & 1403 & 33.5 & & \\
\hline
\end{tabular}

Table 3b. Sleep-related characteristics among former night workers by night work duration. Women who reported having worked at night in the last 10 years were excluded from the analyses. Values are for information reported at the fourth survey (average age of 68.6 years). [SD=standard deviation]

\begin{tabular}{|c|c|c|c|c|c|c|c|c|c|c|c|c|}
\hline \multirow[t]{3}{*}{ Characteristic } & \multicolumn{12}{|c|}{ Former night workers by night work duration } \\
\hline & \multicolumn{4}{|c|}{$<10$ years $(\mathrm{N}=3070)$} & \multicolumn{4}{|c|}{$10-19$ years $(\mathrm{N}=757)$} & \multicolumn{4}{|c|}{$\geq 20$ years $(\mathrm{N}=377)$} \\
\hline & $\mathrm{N}$ & $\%$ & Mean & SD & $\mathrm{N}$ & $\%$ & Mean & SD & $\mathrm{N}$ & $\%$ & Mean & $\mathrm{SD}$ \\
\hline Sleep duration (hours/night) & & & 6.7 & 1.3 & & & 6.6 & 1.4 & & & 6.5 & 1.4 \\
\hline Number of naps per week & & & 2.2 & 2.9 & & & 2.2 & 2.8 & & & 2.2 & 2.7 \\
\hline Poor quality of sleep & 368 & 12.1 & & & 86 & 11.5 & & & 61 & 16.6 & & \\
\hline Take medication to sleep on most days & 203 & 6.8 & & & 55 & 7.5 & & & 33 & 9.1 & & \\
\hline Have trouble falling asleep on most days & 559 & 19.0 & & & 165 & 23.0 & & & 93 & 25.8 & & \\
\hline Wake up too early \& cannot fall asleep on most days & 690 & 23.7 & & & 210 & 29.4 & & & 103 & 29.3 & & \\
\hline Feel refreshed in the morning on most days & 184 & 62.9 & & & 433 & 59.9 & & & 204 & 57.0 & & \\
\hline Almost always feel tired during the day & 160 & 4.5 & & & 62 & 5.9 & & & 32 & 4.3 & & \\
\hline More evening than morning/evening types & 972 & 32.6 & & & 253 & 34.5 & & & 133 & 36.9 & & \\
\hline
\end{tabular}

no significant difference between former and never night workers in the likelihood of taking a nap during the day.

Former night workers were significantly more likely to report poor quality of sleep, take medication to sleep, almost always feel tired during the day, and be an evening- or more of an evening- than a morning-type person. They were also significantly less likely to feel refreshed in the morning than women who had never worked at night.

\section{Characteristics by night work duration}

When we compared the OR of characteristics of short-, medium- and long-duration night workers to never night workers, we found that the likelihood of women possessing certain characteristics varied according to the duration of night work. In total, 16 out of 43 tests showed a significant trend $(\mathrm{P}<0.01)$, whereas 1 or 0 would be expected by chance at this level of significance.

Longer duration of night work was associated with increased likelihood of night workers doing paid work or reporting that the paid employment involved physical effort, and it was associated with decreased likelihood of being married/living with a partner.
While there was no overall difference in the proportion of women who were nulliparous between ever and never night workers, the likelihood of being nulliparous varied significantly among ever night workers, with short-duration night workers less likely (OR 0.84, 99\% CI 0.72-0.98) but long-duration night workers more likely to be nulliparous (OR 1.47, 99\% CI 1.12-1.91) compared to never night workers. Longer duration of night work was also associated with decreased likelihood of having had $\geq 3$ children or having ever used oral contraceptives.

The longer the duration of night work, the greater the likelihood of being obese or a current smoker, or having had high blood pressure.

Longer duration of night work was also associated with decreased likelihood of doing any voluntary work or attending any leisure group.

Among former night workers compared to never night workers, longer duration of night work was associated with (i) a shorter duration of sleep, (ii) having trouble falling asleep for most days, (iii) waking up too early and not falling asleep again for most days, and (iv) a significant decreasing trend in the likelihood of feeling refreshed in the morning for most days. 
Table 4. Odds ratios (OR) for characteristics of women included in these analyses by night work history, adjusted for age and socioeconomic status unless specified. [95\% Cl=95\% confidence interval; $\mathrm{BMI}=$ body mass index]

\begin{tabular}{|c|c|c|c|c|c|c|c|c|c|c|}
\hline \multirow[t]{3}{*}{ Characteristic } & \multirow{2}{*}{\multicolumn{3}{|c|}{ Ever versus never }} & \multicolumn{7}{|c|}{ Duration of night work } \\
\hline & & & & \multicolumn{2}{|c|}{$\begin{array}{l}<10 \text { years } \\
\text { versus never }\end{array}$} & \multicolumn{2}{|c|}{$\begin{array}{l}10-19 \text { years } \\
\text { versus never }\end{array}$} & \multicolumn{2}{|c|}{$\begin{array}{l}\geq 20 \text { years } \\
\text { versus never }\end{array}$} & \multirow[b]{2}{*}{ P-value a } \\
\hline & $\mathrm{OR}$ & $99 \% \mathrm{Cl}$ & $P$ P-value & OR & $99 \% \mathrm{Cl}$ & $\mathrm{OR}$ & $99 \% \mathrm{Cl}$ & $\mathrm{OR}$ & $99 \% \mathrm{Cl}$ & \\
\hline \multicolumn{11}{|l|}{ Sociodemographic factors } \\
\hline Socioeconomic status (in the lower third) $b, c$ & 1.15 & $1.06-1.25$ & $<0.0001$ & 1.06 & $0.95-1.17$ & 1.35 & $1.13-1.60$ & 1.28 & $1.04-1.57$ & 0.005 \\
\hline With college/university degree ${ }^{c}$ & 0.6 & $0.53-0.67$ & $<0.0001$ & 0.61 & $0.53-0.70$ & 0.6 & $0.47-0.78$ & 0.54 & $0.39-0.73$ & 0.4 \\
\hline In paid employment at age $60^{d}$ & 1.21 & $1.11-1.33$ & $<0.0001$ & 1.09 & $0.98-1.22$ & 1.33 & $1.09-1.63$ & 1.84 & $1.44-2.36$ & $<0.0001$ \\
\hline In paid employment at age $65^{\mathrm{e}}$ & 1.19 & $1.08-1.32$ & $<0.0001$ & 1.12 & $0.99-1.27$ & 1.25 & $1.01-1.55$ & 1.52 & $1.18-1.96$ & 0.004 \\
\hline In paid employment at age $69 f$ & 1.28 & $1.15-1.41$ & $<0.0001$ & 1.23 & $1.08-1.39$ & 1.41 & $1.14-1.74$ & 1.41 & $1.09-1.81$ & 0.1 \\
\hline $\begin{array}{l}\text { Any physical effort at work (for paid } \\
\text { employment) }{ }^{c}\end{array}$ & 2.26 & $1.87-2.74$ & $<0.0001$ & 1.74 & $1.38-2.19$ & 3.36 & $2.19-5.15$ & 4.18 & $2.52-6.93$ & $<0.0001$ \\
\hline Married/living with a partner $\mathrm{e}$ & 0.73 & $0.66-0.80$ & $<0.0001$ & 0.79 & $0.70-0.89$ & 0.63 & $.52-0.78$ & 0.62 & $0.49-0.79$ & 0.008 \\
\hline Divorce/separation in last 5 years ${ }^{f}$ & 1.38 & $1.12-1.68$ & 001 & 1.29 & 1.0 & 1.49 & 24 & 1.51 & .44 & 0.4 \\
\hline Death of spouse/partner in last 5 years ${ }^{\dagger}$ & 1.02 & $0.89-1.18$ & 0.7 & 1.01 & $0.85-1.19$ & 1.13 & $0.85-1.51$ & 1.01 & $0.71-1.44$ & 0.9 \\
\hline \multicolumn{11}{|l|}{ Reproductive and hormonal factors } \\
\hline Age of menarche $\left(<13\right.$ years) ${ }^{c}$ & 1.04 & $0.96-1.12$ & 0.2 & 1.04 & $0.95-1.15$ & 1.01 & 0.8 & 1.02 & 0.8 & 0.8 \\
\hline Nulliparous c & 0.99 & $0.88-1.12$ & 0.9 & 0.84 & $0.72-0.98$ & 1.18 & 0.9 & 1.47 & $1.12-1.91$ & $<0.0001$ \\
\hline Number of children $(\geq 3)^{c}$ & 1.43 & $1.32-1.54$ & $<0.0001$ & 1.51 & $1.37-1.66$ & 1.36 & $1.15-1.61$ & 1.16 & $0.94-1.42$ & 0.001 \\
\hline Age of first birth (parous women $\geq 25$ years) ${ }^{c}$ & 0.94 & $0.86-1.02$ & 0.04 & 0.93 & $0.84-1.02$ & 0.97 & $0.81-1.15$ & 0.97 & $0.78-1.20$ & 0.6 \\
\hline Ever oral contraceptive use ${ }^{c}$ & 1.24 & $1.14-1.35$ & $<0.0001$ & 1.32 & $1.19-1.46$ & 1.21 & $1.01-1.45$ & 1.01 & $0.82-1.24$ & 0.002 \\
\hline Ever use of hormone therapy for the menopause ${ }^{f}$ & 1.43 & $1.33-1.55$ & $<0.0001$ & 1.44 & $1.31-1.59$ & 1.4 & $1.19-1.66$ & 1.37 & $1.12-1.68$ & 0.5 \\
\hline \multicolumn{11}{|l|}{ Anthropometric and lifestyle factors } \\
\hline Height $(\geq 165 \mathrm{~cm})^{f}$ & 1.04 & $0.96-1.12$ & 0.2 & 1.05 & 0.9 & 1.06 & -1.26 & 0.97 & & 0.4 \\
\hline $\left.\mathrm{kg} / \mathrm{m}^{2}\right)^{\mathrm{f}}$ & 1.26 & $1.15-1.37$ & $<0.0001$ & 1.17 & & 1.29 & & 1.55 & & 0.002 \\
\hline Current smoker ${ }^{f}$ & 1.37 & $1.19-1.58$ & $<0.0001$ & 1.21 & $1.01-1.44$ & 1.67 & $1.28-2.19$ & 1.63 & $1.18-2.25$ & 0.01 \\
\hline Alcohol consumption ( $\geq 14$ drinks/week) ${ }^{\dagger}$ & 1.11 & $0.99-1.24$ & 0.02 & 1.16 & $1.01-1.33$ & 0.94 & $0.72-1.22$ & 1.1 & $0.82-1.48$ & 0.4 \\
\hline Vigorous physical activity (any/week) ${ }^{\dagger}$ & 1.13 & $1.02-1.26$ & 0.002 & 1.08 & $0.95-1.23$ & 1.06 & $0.84-1.34$ & 1.44 & $1.12-1.86$ & 0.02 \\
\hline Moderate physical activity $(>1 \mathrm{~h}$ & 0.92 & $0.83-1.03$ & 0.07 & 0.95 & $0.83-1.08$ & 0.82 & $0.65-1.03$ & 0.93 & $0.70-1.24$ & 0.7 \\
\hline \multicolumn{11}{|l|}{ Social contacts and activities } \\
\hline In contact with family or frier & 1.19 & $1.10-1.29$ & $<0.0001$ & 1.18 & $1.07-1.30$ & 1.19 & $1.00-1.43$ & 1.2 & -1.48 & 0.8 \\
\hline hers on most days ${ }^{f}$ & 1.25 & $1.11-1.42$ & $<0.0001$ & 1.28 & $1.10-1.49$ & 1.1 & $0.83-1.46$ & 1.34 & $0.98-1.84$ & \\
\hline Do voluntar & 1.25 & $1.14-1.36$ & $<0.0001$ & 1.36 & $1.23-1.51$ & 1.14 & $0.94-1.38$ & 0.94 & $0.74-1.20$ & $<0.0001$ \\
\hline Attend $\mathrm{a}$ & 1.22 & 1.0 & $<0.0001$ & 1.3 & $1.14-$ & 1.13 & $0.88-1.44$ & 1.07 & $0.79-1.44$ & 0.07 \\
\hline Belong & 1.31 & $1.19-1.45$ & $<0.0001$ & 1.4 & $1.25-1.57$ & 1.18 & $0.95-1.46$ & 1.14 & $0.88-1.48$ & 0.03 \\
\hline Attend leisur & 1.04 & $0.95-1.13$ & 0.3 & 1.12 & $1.01-1.25$ & 0.95 & $0.78-1.16$ & 0.83 & $0.65-1.06$ & 0.001 \\
\hline Attenc & 1.03 & $0.95-1.12$ & 0.3 & 1.08 & $0.98-1.19$ & 0.92 & $0.76-1.10$ & 1.01 & $0.82-1.25$ & 0.2 \\
\hline Almost always feel happy ${ }^{\dagger}$ & 0.95 & $0.88-1.02$ & 0.06 & 0.99 & $0.91-1.09$ & 0.89 & $0.76-1.05$ & 0.86 & $0.71-1.05$ & 0.06 \\
\hline \multicolumn{11}{|l|}{ Health indicators } \\
\hline Self-assessed poor overall healt & 1.52 & $1.22-1.89$ & $<0.0001$ & 1.45 & 1.1 & 1.59 & 1.0 & 1.06 & -2.00 & 0.4 \\
\hline sed poor physical fitness ${ }^{f}$ & 1.12 & $0.97-1.28$ & 0.04 & 1.08 & $0.91-1.28$ & 1.15 & $0.86-1.54$ & 1.07 & $0.75-1.53$ & \\
\hline Diabete & 1.24 & $1.09-1.42$ & $<0.0001$ & 1.08 & $0.91-1.28$ & 1.62 & $1.26-2.10$ & 1.3 & $0.93-1.81$ & 0.04 \\
\hline High blood pressure ${ }^{f}$ & 1.05 & $0.98-1.14$ & 0.07 & 1 & $0.91-1.10$ & 1.08 & $0.91-1.27$ & 1.25 & $1.03-1.52$ & 0.006 \\
\hline
\end{tabular}

a Test for trend across the median duration of each category among ever night workers.

${ }^{\mathrm{b}}$ Adjusted for age only

c Values are for information reported at the first (baseline) survey (average age 55.9 years).

d Values are for information reported at the second survey (average age 59.8 years).

${ }^{e}$ Values are for information reported at the third survey (average age 64.9 years).

fValues are for information reported at the fourth survey (average age 68.6 years).

9 Leisure groups including music, singing, dancing, art, craft and bingo groups.

h Fitness groups including fitness, aerobics, yoga, pilates and sports groups.

\section{Discussion}

At an average age of 69 years, 1 in 8 women reported having ever done night work, with only 1 in 50 reporting doing night work for $\geq 20$ years. The majority reporting night work had ceased working at night over 20 years earlier. Nursing was the main work reported among ever night workers, particularly among the long-duration night workers. This is consistent with data from the United Kingdom Labour Force Survey, which showed that for women of working age (16-59 years) in 1993, when participants from the Million Women Study would have been on average 52 years old, shift work was most common in the industrial division comprising public administration, education, and health workers (nearly 1 in 5 workers) (10). 
Table 5. Odds ratios (OR) for sleep-related characteristics among former versus never night workers by night work history, adjusted for age and socioeconomic status. Women who reported having worked at night in the last 10 years were excluded from the analyses. Values are for information reported at the fourth survey (average age 68.6 years).

\begin{tabular}{|c|c|c|c|c|c|c|c|c|c|c|}
\hline \multirow[t]{3}{*}{ Characteristic } & \multirow{2}{*}{\multicolumn{3}{|c|}{$\begin{array}{l}\text { Former versus never } \\
\text { night work }\end{array}$}} & \multicolumn{7}{|c|}{ Duration of night work } \\
\hline & & & & \multicolumn{2}{|c|}{$\begin{array}{c}<10-19 \text { versus } \\
\text { never }\end{array}$} & \multicolumn{2}{|c|}{$\begin{array}{l}10-19 \text { years versus } \\
\text { never }\end{array}$} & \multicolumn{2}{|c|}{$\begin{array}{l}\geq 20 \text { years versus } \\
\text { never }\end{array}$} & \multirow[b]{2}{*}{ P-value a } \\
\hline & OR & $99 \% \mathrm{Cl}$ & P-value & $\mathrm{OR}$ & $99 \% \mathrm{Cl}$ & $\mathrm{OR}$ & $99 \% \mathrm{Cl}$ & $\mathrm{OR}$ & $99 \% \mathrm{Cl}$ & \\
\hline$<6$ hours sleep per night & 1.27 & $1.14-1.42$ & $<0.0001$ & 1.2 & $1.05-1.37$ & 1.35 & $1.05-1.73$ & 1.77 & $1.27-2.45$ & 0.004 \\
\hline$\geq 8$ hours sleep per night & 0.88 & $0.80-0.97$ & 0.0006 & 0.87 & $0.77-0.97$ & 0.97 & $0.78-1.21$ & 0.79 & $0.57-1.09$ & 1 \\
\hline Any nap during the week & 1.02 & $0.94-1.11$ & 0.5 & 1.03 & $0.93-1.14$ & 0.99 & $0.81-1.20$ & 0.96 & $0.73-1.27$ & 0.4 \\
\hline Poor sleep quality & 1.15 & $1.01-1.31$ & 0.004 & 1.13 & $0.97-1.31$ & 1.05 & $0.78-1.42$ & 1.61 & $1.11-2.31$ & 0.07 \\
\hline Take medication to sleep on most days & 1.35 & $1.15-1.60$ & $<0.0001$ & 1.29 & $1.06-1.57$ & 1.4 & $0.97-2.02$ & 1.65 & $1.02-2.65$ & 0.1 \\
\hline Have trouble falling asleep on most days & 1.08 & $0.97-1.20$ & 0.05 & 1 & $0.88-1.13$ & 1.25 & $0.99-1.58$ & 1.42 & $1.04-1.95$ & 0.001 \\
\hline $\begin{array}{l}\text { Wake up too early \& cannot fall asleep } \\
\text { again on most days }\end{array}$ & 1.08 & $0.97-1.19$ & 0.06 & 0.99 & $0.88-1.12$ & 1.31 & $1.06-1.63$ & 1.27 & $0.94-1.73$ & 0.005 \\
\hline $\begin{array}{l}\text { Feel refreshed in the morning on most } \\
\text { days }\end{array}$ & 0.91 & $0.84-0.99$ & 0.007 & 0.96 & $0.87-1.06$ & 0.85 & $0.70-1.04$ & 0.75 & $0.57-0.98$ & 0.009 \\
\hline Almost always feel tired during the day & 1.45 & $1.21-1.73$ & $<0.0001$ & 1.35 & $1.07-1.72$ & 1.92 & $1.30-2.84$ & 1.48 & $0.80-2.74$ & 0.2 \\
\hline More evening than morning/evening types & $s 1.18$ & $1.08-1.29$ & $<0.0001$ & 1.13 & $1.02-1.25$ & 1.23 & $1.00-1.50$ & 1.38 & $1.04-1.83$ & 0.07 \\
\hline
\end{tabular}

a Test for trend across the median duration of each category among former night workers.

In this large prospective cohort, we compared the characteristics of women who had ever and never worked at night, focusing on known risk factors for conditions such as breast cancer and vascular disease, which had been associated with night work. We found important and highly significant differences between ever and never night workers in a range of characteristics, including sociodemographic factors, reproductive history, exogenous hormone use, anthropometric and lifestyle factors, as well as social and sleep-related factors and overall health indicators. We also found variation in many of these characteristics among ever night workers by their duration of night work. Compared to short-duration night workers, long-duration night workers were more likely to be nulliparous, obese, smoke more, and have lower socioeconomic status, and these factors are known to increase the risk of many cancers and vascular disease. Former night workers reported considerable problems with sleep, even when they had not worked at night for at least $\geq 10$ years. These differences will inform the design of future prospective analyses of night work in relation to disease within the cohort.

The socioeconomic and educational differences by night work history observed in the current study are not unexpected, given that the most common work done by night workers was nursing, and at the time when this cohort of women trained to be nurses, a college/ university degree would not have been required. The differences in characteristics by night work history may not necessarily be generalizable and may vary, for example, by sex, age, region, job type and definition of night work (11). Nevertheless, our findings with respect to socioeconomic status are similar to the results from a previous study of nurses in the USA, which showed that ever night workers were more likely to come from lower socioeconomic groups and women from lower socioeconomic groups were more likely to stay in shift work involving night work for longer durations (7).

There are limited published data on relationships and social activities among individuals who have worked at night $(12,13)$. In the current study, we found that, compared to never night workers, ever night workers, especially long-duration night workers, were less likely to be living with a partner and more likely to report a recent divorce/permanent separation but were also more likely to have frequent contact with others.

In our study, ever night workers had more children, but nulliparity varied substantially by duration of night work, with long-duration night workers ( $\geq 20$ years) more likely to be nulliparous. Previous findings on the association between night work and parity were inconsistent $(7,8,14)$. We also found that ever night workers were more likely to have used exogenous hormones. Few other studies have reported on exogenous hormone use among night-working women, although ever use of HRT was found to be less common among rotating night shift workers in the Nurses' Health Study, particularly among long-duration night workers (15). Given the established effects of the reproductive and hormonal factors on the risk of breast cancer (16-18), the differences observed in the current study would put ever night workers, and especially long-duration night workers, at an increased risk of the disease. The differences in family structure and related factors may due to the influence of night work on family life or vice versa; it is possible that women who are not married or living with a partner or are without children are more likely to select and remain in jobs involving night work. 
Women who reported having done night work were more likely than those who did not to be obese and smoke, both of which are major risk factors for many cancers and vascular disease (18). Our findings are consistent with those from previous epidemiological studies, which have also found a higher prevalence of obesity and smoking among shift compared to non-shift workers (5). We did not find a significant difference in alcohol consumption between ever and never night workers, and previous results for alcohol consumption in relation to night work status have not been consistent $(7,8,19)$.

One pathway through which shift work might influence risk of chronic disease is via sleep deprivation and sleep disturbance (4). The acute effects of night work on sleep duration and sleep problems have been previously reported (20), but there are few published data on persistent associations of night work with sleep disturbances later in life. Among women who had not worked at night during the previous 10 years, we found that former night work was associated with an increased risk of current sleep problems and comparatively short sleep durations. Women who reported working at night for $\geq 20$ years were the most likely to report these sleep problems. As with several of the other differences observed, the variation in sleep characteristics between never and ever night workers could be a direct or indirect long-term consequence of night work or may be why women selected and remained in a job involving night work or both.

Chronotype is thought to influence tolerance for night work but few previous large studies have examined the association. Our findings that night workers were more likely to be an evening type and that there was an increasing tendency to be an evening type with increasing duration of night work suggest that evening types might be more likely to select jobs involving night work and to remain in such jobs for longer.

We asked participants about their overall health and well-being, both in terms of how they would rate their overall health and whether they had been told by their doctor that they had diabetes or high blood pressure. The finding that short- and/or medium-duration night workers were more likely to report poor overall health or to have diabetes than long-duration night workers suggests that women who remain in jobs involving nights for a long time may be those who do not have poor health or do not perceive themselves as having poor health (21). However, contrary to these results, we found that long-duration night workers were more likely to report high blood pressure than never night workers. The differences in diabetes and high blood pressure by night work history could affect their risk of vascular disease.

\section{Concluding remarks}

Results from several studies have suggested that people who work at night for $\geq 10$ years may have a higher risk of developing cancer and vascular disease (1). Few studies have reported on the associations between night work and risk factors for these diseases and we found that women who reported having worked at night, especially long-duration night workers, were substantially different from those who reported never having worked at night. Many of the differences, for example, in smoking, obesity, and reproductive and hormonal factors, would put night workers at increased risks of cancer, vascular disease, and other common conditions. These findings highlight the need for careful control of potential confounding in studies of the association between shift work and subsequent risk for disease.

\section{Acknowledgments}

We thank the women who participated in the Million Women Study; the National Health Service (NHS) Breast Screening Centre collaborators [Avon, Aylesbury, Barnsley, Basingstoke, Bedfordshire \& Hertfordshire, Cambridge \& Huntingdon, Chelmsford \& Colchester, Chester, Cornwall, Crewe, Cumbria, Doncaster, Dorset, East Berkshire, East Cheshire, East Devon, East of Scotland, East Suffolk, East Sussex, Gateshead, Gloucestershire, Great Yarmouth, Hereford \& Worcester, Kent (Canterbury, Rochester, Maidstone), Kings Lynn, Leicestershire, Liverpool, Manchester, Milton Keynes, Newcastle, North Birmingham, North East Scotland, North Lancashire, North Middlesex, North Nottingham, North of Scotland, North Tees, North Yorkshire, Nottingham, Oxford, Portsmouth, Rotherham, Sheffield, Shropshire, Somerset, South Birmingham, South East Scotland, South East Staffordshire, South Derbyshire, South Essex, South Lancashire, South West Scotland, Surrey, Warrington Halton St Helens \& Knowsley, Warwickshire Solihull \& Coventry, West Berkshire, West Devon, West London, West Suffolk, West Sussex, Wiltshire, Winchester, Wirral and Wycombe]; the Million Women Study Coordinating Centre (Simon Abbott, Miranda Armstrong, Krys Baker, Angela Balkwill, Vicky Benson, Valerie Beral, Judith Black, Anna Brown, Diana Bull, Benjamin Cairns, James Chivenga, Barbara Crossley, Gabriella Czanner, Dave Ewart, Sarah Ewart, Lee Fletcher, Toral Gathani, Laura Gerrard, Adrian Goodill, Jane Green, Isobel Green, Lynden Guiver, Joy Hooley, Michal Hozak, Sau Wan Kan, Carol Keene, Oksana Kirichek, Mary Kroll, Nicky Langston, MariaJose Luque, Lynn Pank, Kirstin Pirie, Gillian Reeves, Emma Sherman, Moya Simmonds, Elizabeth Spencer, Helena Strange, Sian Sweetland, Alison Timadjer, Sarah 
Tipper, Ruth Travis, Xiao-Si Wang, Joanna Watson, Stephen Williams, Lucy Wright); and the Steering Committee of the Million Women Study (Joan Austoker, Emily Banks, Valerie Beral, Ruth English, Jane Green, Julietta Patnick, Richard Peto, Gillian Reeves, Martin Vessey, and Matthew Wallis). We also thank Benjamin Cairns and Kirstin Pirie for their discussion of statistical methods.

This work was funded by Health and Safety Executive UK, Cancer Research UK, the Medical Research Council, and the NHS Breast Screening Programme.

The authors declare no conflict of interest.

\section{References}

1. Wang XS, Armstrong ME, Cairns BJ, Key TJ, Travis RC. Shift work and chronic disease: the epidemiological evidence. Occup Med (Lond). 2011;61:78-89. http://dx.doi. org/10.1093/occmed/kqr001.

2. Straif K, Baan R, Grosse Y, Secretan B, El Ghissassi F, Bouvard V, et al. Carcinogenicity of shift-work, painting, and fire-fighting. Lancet Oncol. 2007;8:1065-6. http://dx.doi. org/10.1016/S1470-2045(07)70373-X.

3. Frost P, Kolstad HA, Bonde JP. Shift work and the risk of ischemic heart disease - a systematic review of the epidemiologic evidence. Scand J Work Environ Health. 2009;35:163-79. http://dx.doi.org/10.5271/sjweh.1319.

4. Akerstedt T. Shift work and disturbed sleep/wakefulness. Occup Med (Lond). 2003;53:89-94. http://dx.doi. org/10.1093/occmed/kqg046.

5. Zhao I, Turner C. The impact of shift work on people's daily health habits and adverse health outcomes. Australian Journal of Advanced Nursing. 2008;25:8-22.

6. Stevens RG. Light-at-night, circadian disruption and breast cancer: assessment of existing evidence. Int J Epidemiol. 2009;38:963-70. http://dx.doi.org/10.1093/ije/dyp178.

7. Schernhammer ES, Laden F, Speizer FE, Willett WC, Hunter DJ, Kawachi I, et al. Rotating night shifts and risk of breast cancer in women participating in the Nurses' Health Study. J Natl Cancer Inst. 2001;93:1563-8. http://dx.doi.org/10.1093/ jnci/93.20.1563.

8. Schernhammer ES, Kroenke CH, Laden F, Hankinson SE. Night work and risk of breast cancer. Epidemiology. 2006;17:10811. http://dx.doi.org/10.1097/01.ede.0000190539.03500.c1.
9. Townsend P, Phillimore P, Beattie A. Health and deprivation : inequality and the north. London: Croom Helm; 1988.

10. McOrmond T. Changes in working trends over the past decade. Labour Market Trends. 2004;112:25-35.

11. IARC monographs on the evaluation of carcinogenic risks to humans. Painting, Firefighting, and Shiftwork. IARC Monogr Eval Carcinog Risks Hum. 2010;98.

12. Perry-Jenkins M, Goldberg AE, Pierce CP, Sayer AG. Shift Work, Role Overload, and the Transition to Parenthood. J Marriage Fam. 2007;69:123-38. http://dx.doi.org/10.1111/ j.1741-3737.2006.00349.x.

13. Mills M, Täht K. Nonstandard Work Schedules and Partnership Quality: Quantitative and Qualitative Findings. J Marriage Fam. 2010;72:860-75. http://dx.doi.org/10.1111/j.17413737.2010.00735.x

14. Pesch B, Harth V, Rabstein S, Baisch C, Schiffermann M, Pallapies D, et al. Night work and breast cancer - results from the German GENICA study. Scand J Work Environ Health. 2010;36:134-41. http://dx.doi.org/10.5271/sjweh.2890.

15. Viswanathan AN, Hankinson SE, Schernhammer ES. Night shift work and the risk of endometrial cancer. Cancer Res. 2007;67:10618-22. http://dx.doi.org/10.1158/0008-5472. CAN-07-2485.

16. Beral V. Breast cancer and hormone-replacement therapy in the Million Women Study. Lancet. 2003;362:419-27. http:// dx.doi.org/10.1016/S0140-6736(03)14596-5.

17. Reeves GK, Pirie K, Green J, Bull D, Beral V. Reproductive factors and specific histological types of breast cancer: prospective study and meta-analysis. $\mathrm{Br} \mathrm{J}$ Cancer 2009;100:538-44. http://dx.doi.org/10.1038/sj.bjc.6604853.

18. Reeves GK, Pirie K, Beral V, Green J, Spencer E, Bull D. Cancer incidence and mortality in relation to body mass index in the Million Women Study: cohort study. BMJ. 2007;335:1134. http://dx.doi.org/10.1136/bmj.39367.495995.AE.

19. Bushnell PT, Colombi A, Caruso CC, Tak S. Work schedules and health behavior outcomes at a large manufacturer. Ind Health. 2010;48:395-405. http://dx.doi.org/10.2486/ indhealth.MSSW-03.

20. Akerstedt T, Wright KP Jr. Sleep Loss and Fatigue in Shift Work and Shift Work Disorder. Sleep Med Clin. 2009;4:25771. http://dx.doi.org/10.1016/j.jsmc.2009.03.001.

21. Kolstad HA. Nightshift work and risk of breast cancer and other cancers--a critical review of the epidemiologic evidence. Scand J Work Environ Health. 2008;34:5-22. http://dx.doi. org/10.5271/sjweh.1194.

Received for publication: 13 January 2012 